Research article Open Access

\title{
Chromosomal instability and lack of cyclin E regulation in hCdc4 mutant human breast cancer cells
}

\author{
Nicole E Willmarth ${ }^{1,2}$, Donna G Albertson ${ }^{3}$ and Stephen P Ethier ${ }^{2}$
}

\author{
1Department of Cellular and Molecular Biology, The University of Michigan, Ann Arbor, Michigan, USA \\ 2Department of Radiation Oncology, Division of Radiation and Cancer Biology, The University of Michigan Health System, and the University of \\ Michigan Comprehensive Cancer Center, Ann Arbor, Michigan, USA \\ ${ }^{3}$ Cancer Research Institute, University of California San Francisco, San Francisco, California, USA \\ Corresponding author: Stephen P Ethier, spethier@med.umich.edu
}

Received: 26 Jan 2004 Revisions requested: 4 Mar 2004 Revisions received: 14 May 2004 Accepted: 26 May 2004 Published: 6 Jul 2004

Breast Cancer Res 2004, 6:R531-R539 (DOI 10.1186/bcr900)

(C) 2004 Willmarth et al.; licensee BioMed Central Ltd. This is an Open Access article: verbatim copying and redistribution of this article are permitted in all media for any purpose, provided this notice is preserved along with the article's original URL.

\begin{abstract}
Introduction Cyclin $E$, a $G_{1}$ cyclin essential for $G_{1}-S$ phase transition, is known to have a profound effect on tumorigenesis. Elevated levels of cyclin $E$ have been associated with breast cancer, and chromosomal instability observed in breast cancer is suggested to be associated with constitutive expression of cyclin E. It was previously demonstrated that SUM149PT human breast cancer cells show very high levels of cyclin E expression by western analysis and that they express a nonfunctional cyclin E ubiquitin ligase due to a mutation in the F-box protein hCdc4.

Methods We examined cyclin E expression in both MCF10A and SUM149PT cells using western blot analysis and flow cytometry. Immunofluorescence was utilized for the localization of cyclin $E$ in both normal and breast cancer cells. In addition, array comparative genomic hybridization analysis was performed to compare chromosome copy number alterations with levels of cyclin $E$ expression among a panel of breast cancer cell lines.
\end{abstract}

Results SUM149PT cells overexpress cyclin E on a cell per cell basis for the duration of the cell cycle. High cyclin E levels are maintained throughout the S phase, and SUM149PT cells exhibit an $S$ phase delay or arrest probably due to cyclin $E$ overexpression. In addition, comparative genomic hybridization indicated that SUM149PT cells exhibit many chromosome copy number alterations, which may reflect prior or ongoing genomic instability. However, no direct correlation was observed between cyclin $\mathrm{E}$ levels and genomic copy number alteration in a panel of human breast cancer cell lines.

Conclusions Cyclin $\mathrm{E}$ is overexpressed at high levels throughout the cell cycle in SUM149PT cells, which is in stark contrast to cyclin $\mathrm{E}$ degradation observed in the mid to late $\mathrm{S}$ phase of normal cells. SUM149PT cells are unable to regulate cyclin $\mathrm{E}$ and also exhibit many copy number alterations. However, there was a lack of direct correlation between cyclin E overexpression and chromosomal instability across a panel of other breast cancer cell lines examined.

Keywords: breast cancer, cyclin E, genomic instability

\section{Introduction}

Cyclin $E$ is a $G_{1}$ cyclin that complexes with cyclin-dependent kinase 2 to regulate cell transit from the $G_{1}$ phase to the $S$ phase of the cell cycle. Under normal conditions, cyclin $E$ accumulates in the nucleus at the $G_{1} / S$ phase boundary and is degraded as cells progress through the $S$ phase [13]. This firm regulation of cell growth by cyclin $E$ is often lost in cancer. Many human breast cancers have cyclin $\mathrm{E}$ present constitutively in an active cyclin-dependent kinase 2 complex, and a correlation between cyclin E overexpression and human breast cancer has been demonstrated $[4,5]$.
Failure to properly regulate cyclin E can lead to phosphorylation of substrates at inappropriate times during the cell cycle, consequently eliminating important checkpoint controls. Accelerated $S$ phase entry, tumorigenesis and genetic instability have all been found to be consequences of cyclin $E$ deregulation [6-9]. Constitutive expression of cyclin E may lead to chromosomal instability, as proper regulation of cyclin $E$ is critical for the fidelity of chromosome transmission. Defective regulation of these processes can produce chromosomal aberrations, and it has been shown that overexpression of cyclin $E$ induces chromosomal aneuploidy in human mammary epithelial (HME) cells [8]. 
Regulation of cyclin E is dependent upon SCF ubiquitin ligase activity $[10,11]$. SCF is a ubiquitin ligase that targets a number of proteins, including cyclin $\mathrm{E}$, for ubiquitin-mediated proteolysis. SCF has three main subunits: Skp1, Cdc53/Cul-1, and Rbx1 [12]. An F-box protein forms the variable component, which determines the substrate specificity of the SCF ubiquitin ligase. SCF was first suggested to be involved in cyclin $E$ degradation when levels of cyclin E were found to be elevated in Cul-1\% embryos $[11,12]$. When three thermosensitive mutants of the most characterized F-box proteins in yeast were examined, the cdc4 mutant was the only one to stabilize cyclin E [13]. In addition, a dominant negative hCdc4 allele transduced into KB cells led to the accumulation of cyclin E [13]. The F-box protein hCdc4 therefore appears to be the critical component for cyclin $E$ turnover in normal cells.

Western blot analysis of cyclin E protein levels in a panel of breast cancer cell lines demonstrated that SUM149PT breast cancer cells possess extremely high levels of cyclin E. The SUM149PT cell line has also been shown to possess a mutation at the hCdc4 locus, eliminating the last four of seven WD40 repeats thought to be important for interaction with the SCF ubiquitin ligase $[13,14]$. Taken together, these results make this cell line a good model for investigating cyclin $\mathrm{E}$ regulation and its association with chromosomal instability in breast cancer.

Since cyclin E is normally degraded as cells enter the $S$ phase, it is still uncertain whether the high levels of cyclin $E$ protein in SUM149PT cells observed by western blot analysis are due to a high proportion of the population stabilizing normal levels, or whether cyclin $E$ is overexpressed to high levels on a per cell basis.

In the present article, we demonstrate that cyclin $\mathrm{E}$ is highly overexpressed on a per cell basis in the SUM149PT cell line relative to a large panel of human breast cancer cell lines. We further show that this overexpression remains throughout the cell cycle. Very high cyclin E levels are maintained throughout the $S$ phase, which is in stark contrast to cyclin E degradation observed in the mid to late $S$ phase of normal cells. In addition, we also observed an accumulation of cells in the $S$ phase of the cell cycle that may be a direct effect of cyclin E overexpression. We found overexpression of cyclin $E$ in the nucleus and in the cytoplasm of SUM149PT cells, whereas cyclin E was centralized at low levels to the nucleus in normal cells. While SUM149PT cells did exhibit many DNA copy number aberrations, a direct correlation with cyclin $\mathrm{E}$ overexpression and the number of genomic aberrations, as determined by array comparative genomic hybridization $(\mathrm{aCGH})$, was not observed in the panel of breast cancer cells we examined.

\section{Materials and methods}

\section{Materials, cell lines, and culture conditions}

MCF10A cells were maintained in SFIHE medium (Ham's F-12 with 5\% BSA [Gibco, Carlsbad, CA, USA], $0.5 \mu \mathrm{g} / \mathrm{ml}$ fungizone, $5 \mu \mathrm{g} / \mathrm{ml}$ gentamycin, $5 \mathrm{mM}$ ethanolamine, 10 mM HEPES, $10 \mu \mathrm{M}$ transferrin, $10 \mu \mathrm{M}$ 3,3,'5-Triiodo- ${ }^{-}$-Thyronine (T3), $50 \mu \mathrm{M}$ sodium selenite, $5 \mu \mathrm{g} / \mathrm{ml}$ insulin, $1 \mu \mathrm{g} /$ $\mathrm{ml}$ hydrocortisone, and $10 \mathrm{ng} / \mathrm{ml}$ epidermal growth factor (EGF). SUM149PT cells were maintained in 5\% IH (Ham's $\mathrm{F}-12$ with $5 \%$ fetal bovine serum [Gibco] with $5 \mu \mathrm{g} / \mathrm{ml}$ insulin and $1 \mu \mathrm{g} / \mathrm{ml}$ hydrocortisone).

The culture conditions for the immortalized normal cell line MCF10A and the human breast cancer cell lines (SUM44, SUM52, SUM102, SUM149PT, SUM152, SUM190, SUM225, SUM229 and SUM1315MO2) were as described previously [15]. All cells were cultured at $37^{\circ} \mathrm{C}$ in a humidified incubator containing $10 \% \mathrm{CO}_{2}$ and were maintained free of mycoplasm.

\section{Western blot analysis}

Whole cell lysates were prepared using RIPA lysis buffer (1\% deoxycholic acid, 1\% Triton X-100, 0.1\% SDS, 250 $\mathrm{mM} \mathrm{NaCl}$ and $50 \mathrm{mM}$ Tris- $\mathrm{HCl}, \mathrm{pH} \mathrm{7.5)}$ and were sonicated. The whole cell lysates were cleared by centrifugation and the amounts of protein were quantified by performing a protein assay. The samples were boiled in loading buffer, and $100 \mu \mathrm{g}$ was loaded into the wells of 10\% SDS-polyacrylamide gels. After electrophoresis, proteins were electroblotted onto polyvinylidene difluoride (Immobilon-P, Millipore, Billerica, MA, USA) membranes overnight. Membranes were then blocked in TTBS $(0.1 \%$ [v/v] Tween 20, $100 \mathrm{mM}$ Tris, $0.9 \% \mathrm{NaCl}, \mathrm{pH} 7.5)$ containing 5\% BSA for 1 hour at room temperature and were probed with a 1:1000 dilution of a mouse monoclonal antibody against cyclin E (HE12; Santa Cruz Technologies, Santa Cruz, CA, USA). Membranes were probed with biotinylated anti-mouse secondary antibodies, and bound antibody was detected using streptavidin-conjugated horseradish peroxidase (HRP) and diaminobenzidine tetrahydrochloride colorimetric substrate $(100 \mu \mathrm{l}$ of $40 \mathrm{mg} / \mathrm{ml}$ diaminobenzidine tetrahydrochloride, $25 \mu \mathrm{l}$ of $80 \mathrm{mg} / \mathrm{ml}$ $\mathrm{NiCl}_{2}$, and $1.5 \mu$ of $30 \% \mathrm{H}_{2} \mathrm{O}_{2}$ ).

\section{Sorting and analysis of fluorescent labeled cells}

Cells were harvested and resuspended in ice-cold PBS, were fixed and permeabilized using 100\% ethanol (20 min at $4^{\circ} \mathrm{C}$ ), and were washed with PBS. The cells were then incubated first with primary cyclin $E$ antibody (HE12) for 1 hour, were washed with PBS and were then incubated with secondary anti-mouse FITC antibody for 1 hour. The cells were then subjected to sorting with a fluorescence activated cell sorter (FACSCalibur; BD Biosciences, San Jose, CA, USA) in the University of Michigan CCGC flow cytometry core. For DNA content analysis, the fixed cells were 
treated with RNase $\left(1.0 \mathrm{mg} / \mathrm{ml}\right.$ in PBS) for $30 \mathrm{~min}$ at $37^{\circ} \mathrm{C}$, were washed once with PBS and were stained in $500 \mu \mathrm{l}$ propidium iodide ( $50 \mu \mathrm{g} / \mathrm{ml}$ in PBS) for $15 \mathrm{~min}$ at room temperature. Trout erythrocyte nuclei $\left(7 \times 10^{4}\right.$ nuclei/sample) were used as an internal control. The cell cycle phase distribution was determined by analytical DNA flow cytometry.

\section{Immunofluorescence}

Cells were plated on chamber slides at $37^{\circ} \mathrm{C}$ overnight. Slides were washed with PBS, were fixed with $3.7 \%$ paraformaldehyde for $15 \mathrm{~min}$ at room temperature and were washed again with PBS. Cells were incubated for $20 \mathrm{~min}$ at room temperature in 5\% BSA/0.1\% Triton-X100 to block nonspecific sites and to permeabilize the cells. Slides were incubated with $100 \mu \mathrm{l}$ of 1:1000 dilution of the cyclin $\mathrm{E}$ antibody for 1 hour at $37^{\circ} \mathrm{C}$, were washed and were then incubated with $100 \mu$ of 1:1000 dilution of secondary FITC-conjugated anti-mouse antibody for 1 hour at $37^{\circ} \mathrm{C}$. Control cells were stained with secondary antibody alone. Slides were washed and a cover slip was applied using aquapolymount (Polysciences, Inc. Warrington, PA, USA). Cyclin $\mathrm{E}$ was visualized by fluorescence microscopy.

\section{Comparative genomic hybridization}

The aCGH was carried out as described previously $[16,17]$ using arrays of BAC clones each printed in triplicate. Fluorescently labeled test and reference DNAs (labeled with either cyanine 3 (Сy3) for tumor cells or cyanine 5 (Cy5) for normal cells) were hybridized and DNA losses, gains or amplifications were measured by relative fluorescence ratios.

\section{Results \\ Overexpression of cyclin E in SUM149PT cells}

To determine the relative levels of cyclin E in SUM149PT cells as compared to normal cells, we began by performing a western blot analysis on whole cell lysates using a monoclonal antibody directed specifically toward the C-terminus of cyclin E protein (HE12; Santa Cruz). Cell lines used in this experiment were SUM149PT human breast cancer cells and MCF10A cells, a near diploid spontaneously immortalized cell line that expresses normal cyclin $E$ levels $[4,18]$.

As expected, based on published data [13], these analyses revealed a significantly overexpressed $50 \mathrm{kDa}$ cyclin $\mathrm{E}$ protein in SUM149PT cells when compared with MCF10A cells (Fig. 1a). Two less abundant lower molecular weight forms of cyclin E running at $\sim 42 \mathrm{kDa}$ and $\sim 35 \mathrm{kDa}$ were also identified in SUM149PT cells, in agreement with previous studies showing that processing of cyclin $E$ differs between normal cells and breast tumor cells [19-21]. However, the question remained as to whether elevated levels of the $50 \mathrm{kDa}$ cyclin E protein in SUM149PT cells were due to a high proportion of cells expressing normal levels of cyclin $\mathrm{E}$ or to a true overexpression of the protein on a per cell basis. In order to address this question, we performed fluorescence-activated cell sorting analysis to measure cyclin $\mathrm{E}$ levels in individual cells.

A one-parameter flow cytometric analysis was carried out to measure the cyclin E levels of MCF10A and SUM149PT breast cancer cells. Fixed cells were incubated in antihuman mouse cyclin $\mathrm{E}$ monoclonal primary antibody and then incubated in FITC-coupled secondary anti-mouse antibody. As represented by the peak in Fig. 1b, only a slightly higher amount of FITC fluorescence was observed in the cyclin E-positive MCF10A cells when compared with background FITC levels. Overall cyclin E levels are low in MCF10A cells due to the fact that these cells were not synchronized, and therefore only a small fraction of the population was expressing cyclin E. In contrast, we observed an approximately twofold to threefold cyclin E/FITC positive peak shift in SUM149PT cells (Fig. 1b). These results suggested that SUM149PT cells were expressing dramatically increased levels of cyclin $\mathrm{E}$ protein when compared with MCF10A cells, and that the proportion of cyclin E-positive cells was also increased. An increase in peak height alone would have indicated that more cells were expressing normal levels of cyclin $E$ rather than overexpressing cyclin $E$. These results indicate that cyclin $E$ is overexpressed in SUM149PT cells on a cell per cell basis.

\section{Cyclin E is overexpressed throughout the cell cycle in SUM149PT cells}

Due to the hCdc4 mutation in SUM149PT cells that prevents targeting cyclin $\mathrm{E}$ for degradation, we hypothesized that cyclin $\mathrm{E}$ would be overexpressed throughout the cell cycle. To gain insight into the expression pattern of cyclin E, two-parameter flow cytometric analysis was performed. Proliferating MCF10A cells and SUM149PT cells were first incubated with cyclin $\mathrm{E}$ monoclonal antibody and then with FITC-coupled anti-mouse secondary antibody. The cells were stained with $0.5 \mathrm{ml}$ propidium idodide and analyzed by flow cytometry for DNA content (Fig. 2).

The results revealed that $\sim 38 \%$ of cycling MCF10A cells were positive for cyclin $E$ protein. Cells in the $G_{1}$ phase showed the highest expression and, surprisingly, cells in the $\mathrm{G}_{2} / \mathrm{M}$ phase also showed some moderate expression of cyclin $E$ (Fig. 2a). In comparison, $\sim 98 \%$ of cycling SUM149PT cells were cyclin E-positive, including those in the $S$ phase, the $G_{2}$ phase and the $M$ phase of the cell cycle (Fig. 2b). In addition, cyclin $E$ levels in positive cells were generally higher than in control cells, in agreement with the results already described. These results demonstrate that overexpression of cyclin $E$ protein occurs in all phases of the SUM149PT cell cycle, and that cyclin E is not being degraded at the mid $\mathrm{S}$ phase. 
Figure 1

(a)

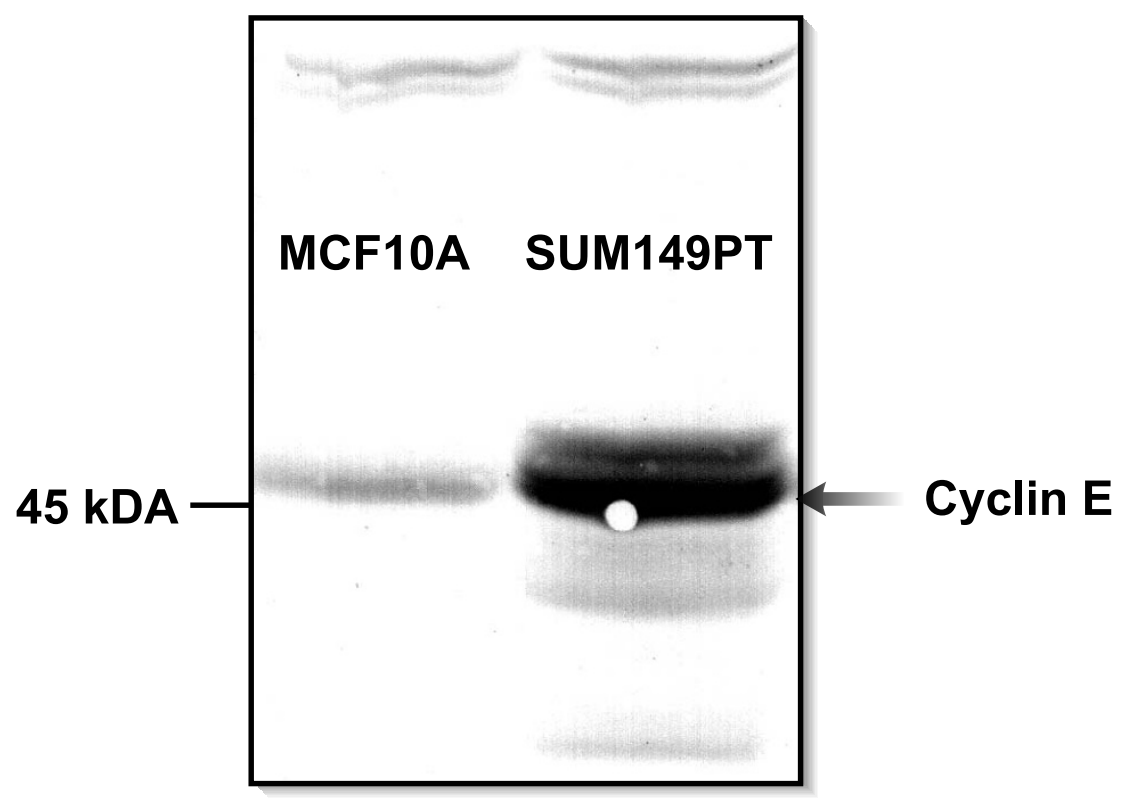

(b)
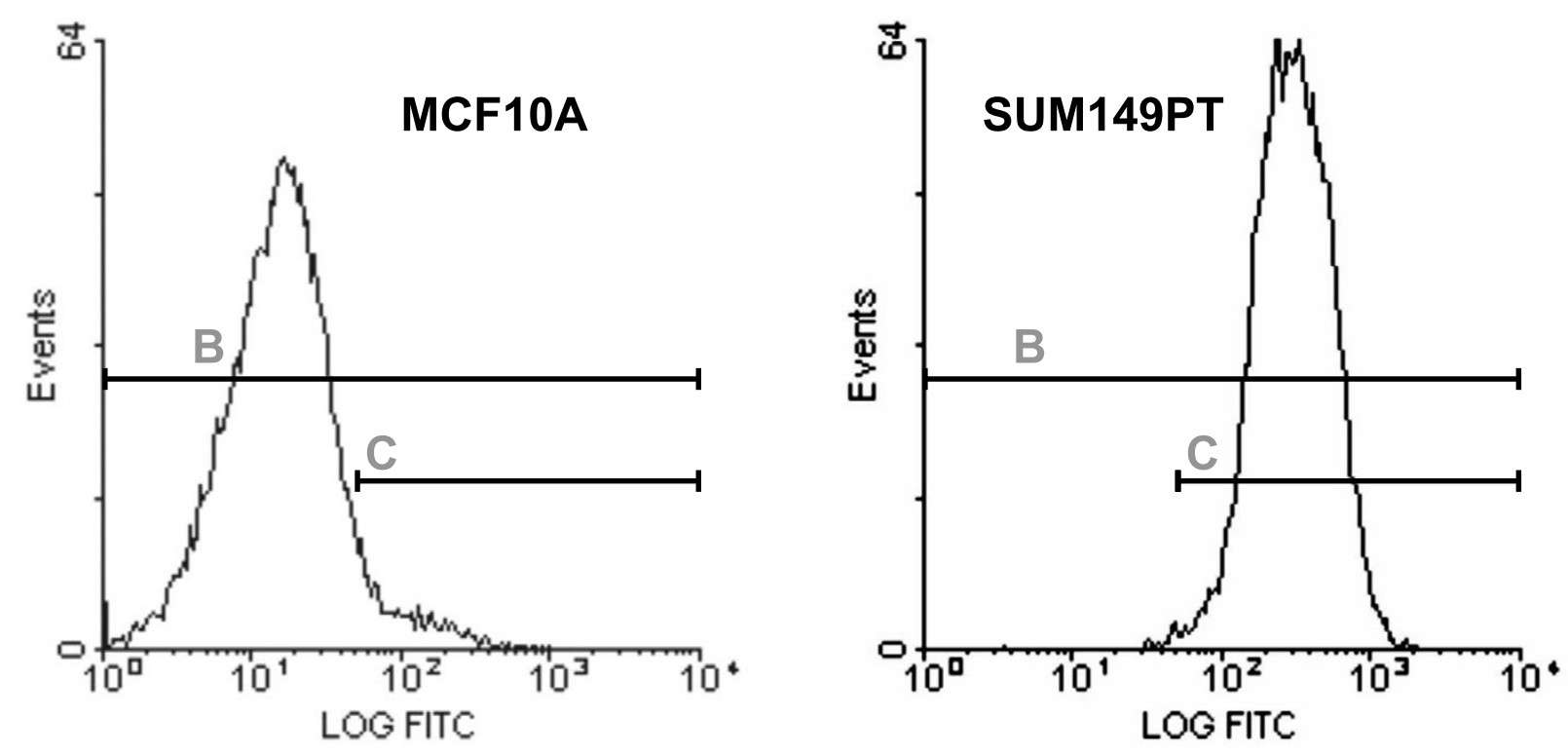

Cyclin E protein is overexpressed on a per cell basis in SUM149PT cells. (a) HE12 cyclin E antibody was used to detect cyclin E by immunoblotting MCF10A and SUM149PT whole cell lysates. (b) One-parameter flow cytometric analysis was performed on fixed and permeabilized cells using HE1 2 cyclin E primary antibody and FITC secondary antibody. Cyclin E levels were twofold to threefold higher in SUM149PT cells than in MCF10A cells. The $B$ gate shows the entire range of fluorescence and the $\mathrm{C}$ gate shows the range of fluorescence that did not overlap with the negative control.

By examining the DNA histograms showing cell cycle progression of the MCF10A (Fig. 3a) and SUM149PT cell lines (Fig. 3b), we found SUM149PT cells have significantly fewer cells in the $G_{1}$ phase than in MCF10A cells $(\sim 35 \%$ versus $\sim 67.8 \%$ in MCF10A cells). In addition, almost one-half $(\sim 45 \%)$ of SUM149PT cells were in the S phase while only $\sim 8.5 \%$ of MCF10A cells were in the S phase. These results are consistent with previous data demonstrating an increase of $\mathrm{G}_{1}-\mathrm{S}$ phase progression in cyclin $\mathrm{E}$ overexpressing HeLa cells [7]. We also observed a sharp peak at the beginning of the S phase in SUM149PT cells (Fig. 4b), in contrast to the flat plateau observed in the $S$ phase of MCF10A cells (Fig. 4a). This observation suggests that SUM149PT cells progress from the $G_{1}$ phase 
(a)

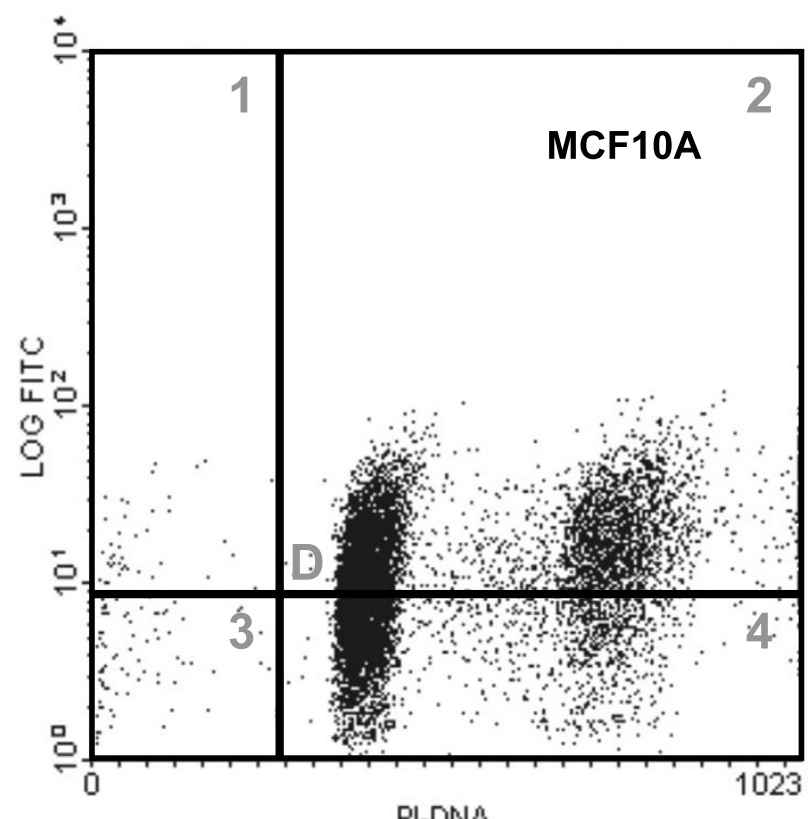

(b)

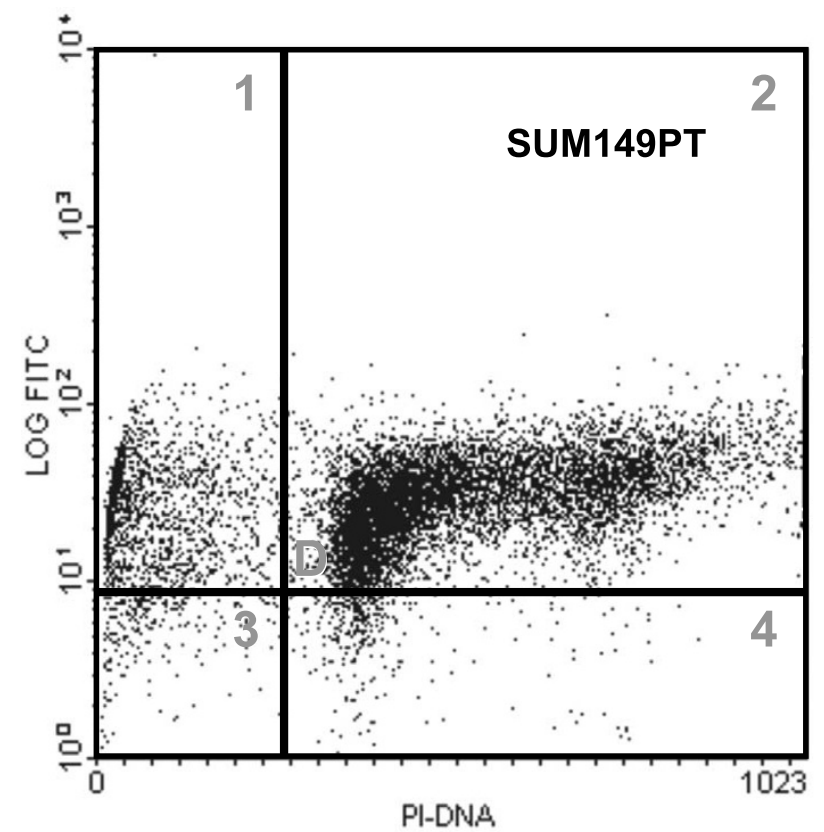

Cyclin E is overexpressed throughout the cell cycle in SUM149PT cells. Two-parameter flow cytometric analysis was performed using fixed and permeabilized (a) MCF10A cells and (b) SUM149PT cells. HE1 2 cyclin E primary monoclonal antibody and FITC-conjugated secondary antibody were used for cyclin $\mathrm{E}$ detection. Cells were incubated with $50 \mu \mathrm{g} / \mathrm{ml}$ propidium iodide (PI) for DNA content analysis.

(a)

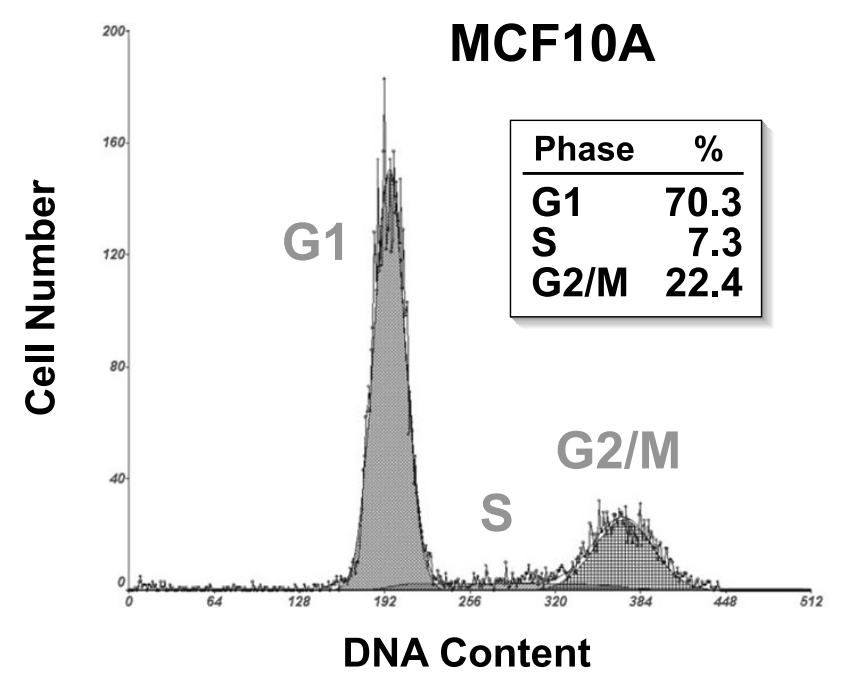

(b)

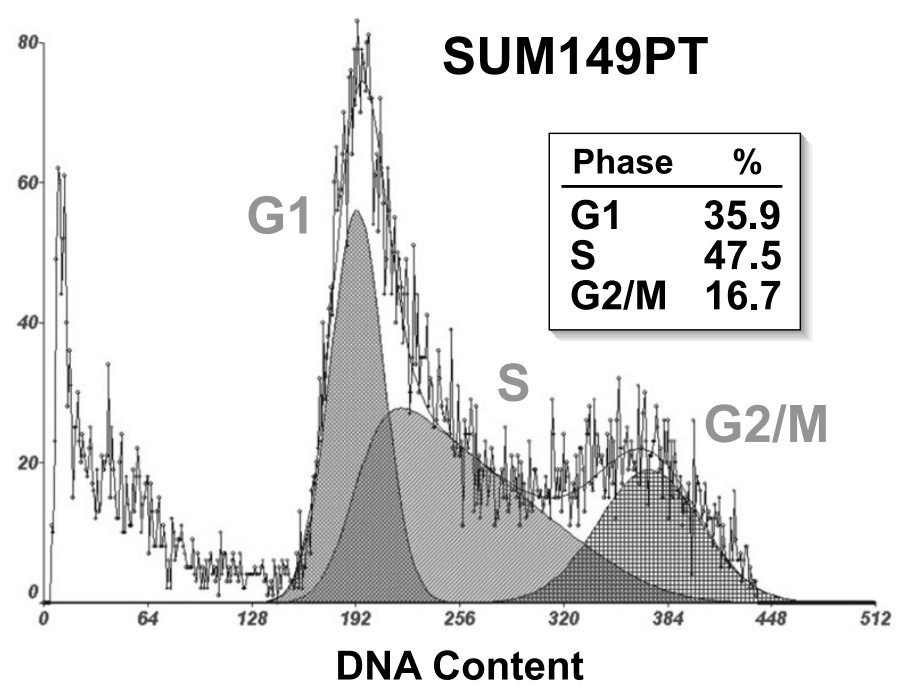

SUM149PT cells exhibit cell cycle arrest in the S phase. Propidium iodide staining shows that SUM149PT cells (b) have significantly fewer cells in the $\mathrm{G}_{1}$ phase than MCF10A cells (a). Almost $50 \%$ of cycling SUM149PT cells are in the $S$ phase, and the sharp peak suggests that some cells are experiencing S-phase delay or arrest. 
(a)

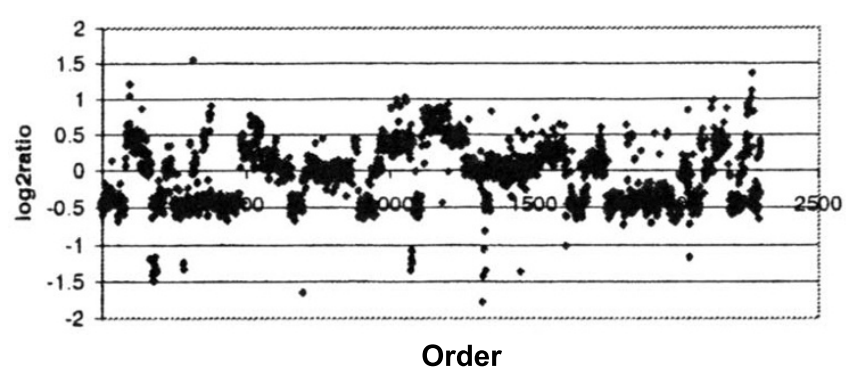

(c)

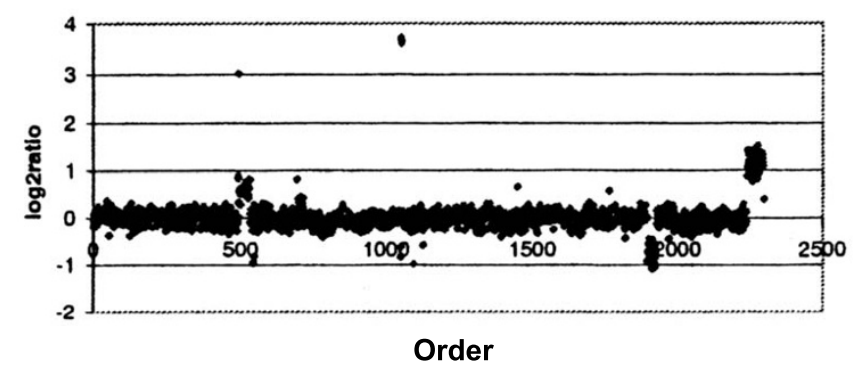

(b)

All

SUM149PT

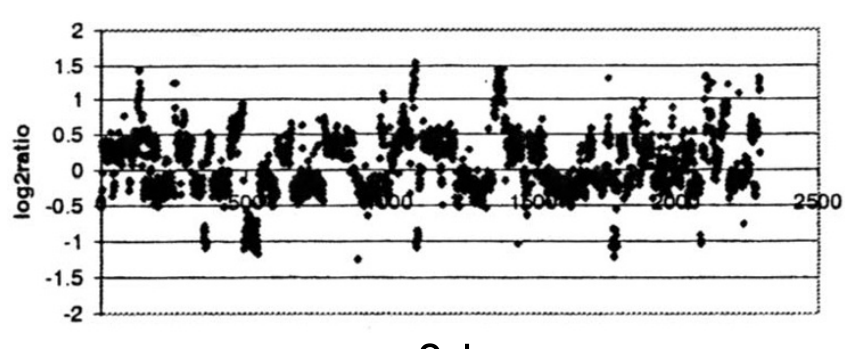

Order

(d)

All

SUM225

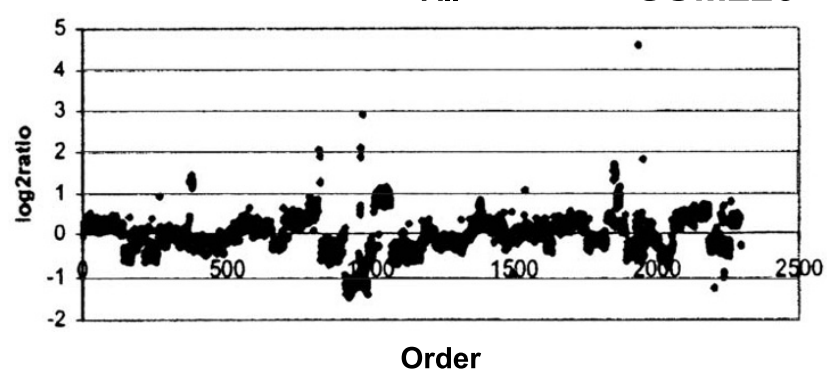

Genomic copy number profiles of cell lines. Array comparative genomic hybridization analysis was performed on a panel of human breast cancer cells in order to map the DNA sequence copy number variation throughout the entire genome. The data are plotted as the $\log _{2}$ ratio for each BAC clone ordered across the genome from 1 pter to Xqter. The reference DNA was male. The SUM185 cell lines (a) and SUM149PT cell lines (b) showed many copy number changes, while other breast cancer cells such as SUM159 cell lines (c) and SUM225 cell lines (d) had a basically normal genome with a few low-level copy number changes and focal amplifications.

into the $\mathrm{S}$ phase of the cell cycle but are unable to proceed through the $S$ phase when high levels of cyclin E persist, resulting in an apparent $S$ phase delay or arrest in these cells.

\section{Association between cyclin E overexpression and genomic instability}

There is considerable evidence that constitutive overexpression of cyclin $E$ accelerates the $G_{1}-S$ phase transition, which can result in premature initiation of DNA synthesis. There is also support for the hypothesis that sustained levels of cyclin E may be responsible for the chromosomal instability observed in breast cancer [8].

In order to determine whether cyclin E overexpression correlated with genomic instability in our panel of human breast cancer cell lines, we utilized aCGH analysis to examine the DNA copy number alterations throughout the genome, and utilized western blot analysis to measure cyclin E protein levels. The results of these experiments are summarized in Figs 4 and 5. SUM149PT cells, which express the highest levels of cyclin $\mathrm{E}$, also exhibited a highly unstable genome as the aCGH analysis demonstrated copy number alterations in virtually every chromosome.
SUM185 cells showed a similar pattern of DNA copy number changes, but these cells expressed relatively low levels of cyclin $E$, which were even lower than those in the MCF10A control cells.

By contrast, the SUM159 cell line, which by aCGH exhibited very few copy number changes characterized by two highly focal areas of gene amplification, expressed cyclin E levels similar to the other cell lines in the panel and significantly lower than SUM149 cells. SUM225 cells, which exhibited several areas of focal gene amplification and loss, expressed similar levels of cyclin E as SUM159 cells and other cell lines in the panel. Thus, whereas most of the breast cancer cell lines express cyclin $E$ levels higher then the MCF10A cells, only the SUM149PT cells dramatically overexpress cyclin E as a result of the hCDC4 mutation in these cells. Furthermore, there was no simple correlation between the levels of cyclin E expression and the degree or type of chromosomal instability as measured by aCGH.

\section{Cyclin E localization in SUM149PT cells}

It has been well established that the endogenous full-length form of cyclin $E$ is predominantly nuclear in normal cells and expressed only at the $G_{1}-S$ phase transition of the cell cycle 


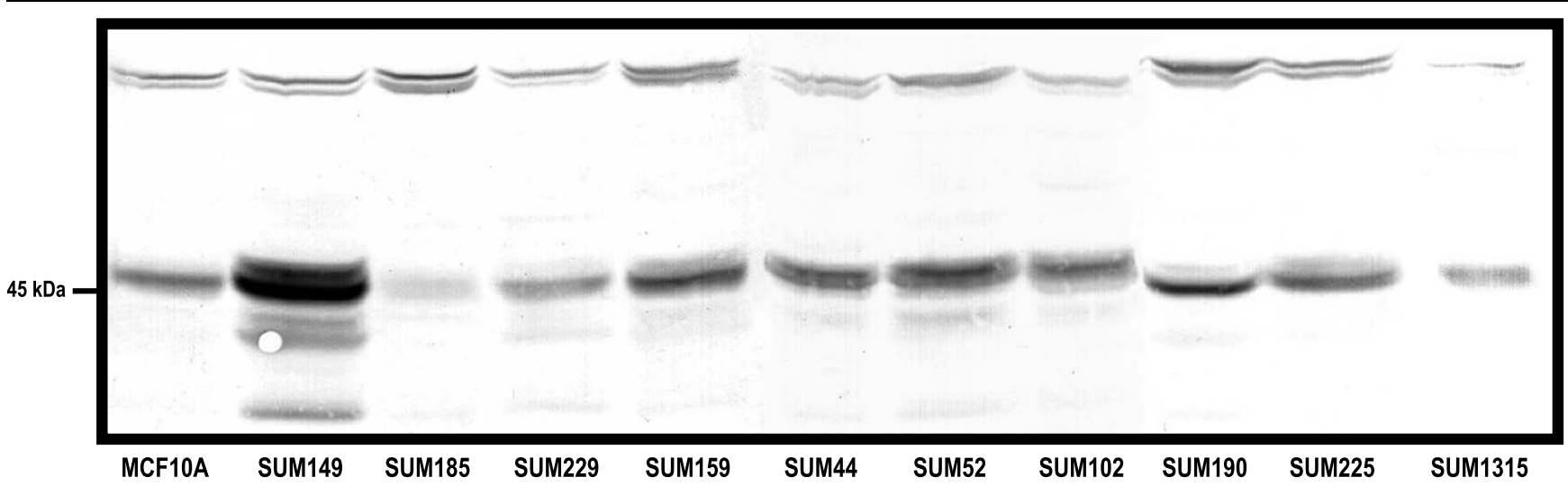

Cyclin E expression in a panel of breast cancer cell lines. Analysis of cyclin E levels in normal cell lines versus tumor breast epithelial cell lines using HE12 cyclin E antibody for immunoblotting.

[3]. To determine the subcellular localization of the overexpressed cyclin E in SUM149PT cells, cells were cultured on chamber slides and labeled as in previous experiments with cyclin E primary antibody (HE12) and FITC-coupled secondary antibody, and were visualized by fluorescence microscopy.

The fluorescence images in Fig. $6 \mathrm{~b}$ show cyclin $\mathrm{E}$ was expressed at low levels in the nucleus of MCF10A cells, yet not in every cell. In SUM149PT cells (Fig. 6d), cyclin E protein overexpression was observed in the nucleus of every cell and some expression was also observed in the cytoplasm.

\section{Discussion \\ Cyclin E overexpression in hCdc4 mutant breast cancer cells}

Our results, and data from other studies employing methods to inhibit the hCdc4 protein, show that hCdc4 plays a major role in cyclin $\mathrm{E}$ degradation. It has been demonstrated by others that hCdc4 mutations stabilize cyclin $\mathrm{E}$ in drosophila and yeast [13,22]. A number of human cancers such as ovarian cancer, breast cancer and endometrial cancer have also been shown to possess hCdc4 mutations as well as high levels of cyclin $E[13,22,23]$. However, it was not understood until now whether cyclin $E$ is being maintained at normal levels throughout the cell cycle or is actually accumulating during the cell cycle in tumors with inactivating hCdc4 mutations.

We examined the cyclin $\mathrm{E}$ levels of an hCdc4 mutant human breast cancer cell line, SUM149PT, and found that cyclin $E$ was overexpressed with levels up to threefold greater than normal cells on a per cell basis. Cyclin E overexpression in these cells was not restricted to the $G_{1}-S$ phase transition where cyclin $E$ is normally expressed, but instead occurred at stabilized levels throughout the cell cycle. Cyclin $\mathrm{E}$ is therefore not being properly regulated in these cells, most probably due to the fact that hCdc4 cannot target cyclin E for degradation. Since the hCdc4 F-box protein has proven to be the determining factor regulating cyclin E degradation [24], our results give further support to the notion that hCdc4 may act as a tumor suppressor.

SUM149PT cells had a high number of cells in the $S$ phase of the cell cycle, consistent with previous data showing that cyclin $E$ overexpression accelerates the $G_{1}-S$ phase transition [7]. We show that in contrast to the plateau observed in the S phase of normal cells, SUM149PT cells have an abnormal DNA histogram characterized by a large $S$ phase peak (Fig. 3b). This S phase delay or arrest suggests that these cells are unable to progress through the $S$ phase, which may be due to the fact that high cyclin $E$ levels persist. This has been demonstrated by previous experiments in which constitutive cyclin $E$ expression induced $S$ phase arrest in normal HME cells [8]. In addition, we showed that cyclin E localization in the SUM149PT cells is predominantly but not exclusively nuclear. It is not clear at this point why some cyclin $E$ is observed in the cytoplasm of SUM149PT cells.

The many genome copy number changes observed in SUM149PT cells may be directly associated with cyclin E overexpression. The $\mathrm{G}_{1}$ checkpoint is critical to prevent genomic instability by regulating DNA repair and progression through the cell cycle. It is therefore possible that overexpressing cyclin E may potentiate chromosomal instability by virtue of premature phosphorylation of its substrates and replication of damaged DNA. Indeed, it has been shown that overexpressing cyclin $\mathrm{E}$ induces chromosomal aneuploidy in HME cells and colorectal cancer cells $[8,25]$. On the contrary, we found no direct correlation between cyclin $\mathrm{E}$ overexpression and chromosomal instability in a panel of other breast cancer cells lines we exam- 
Figure 6
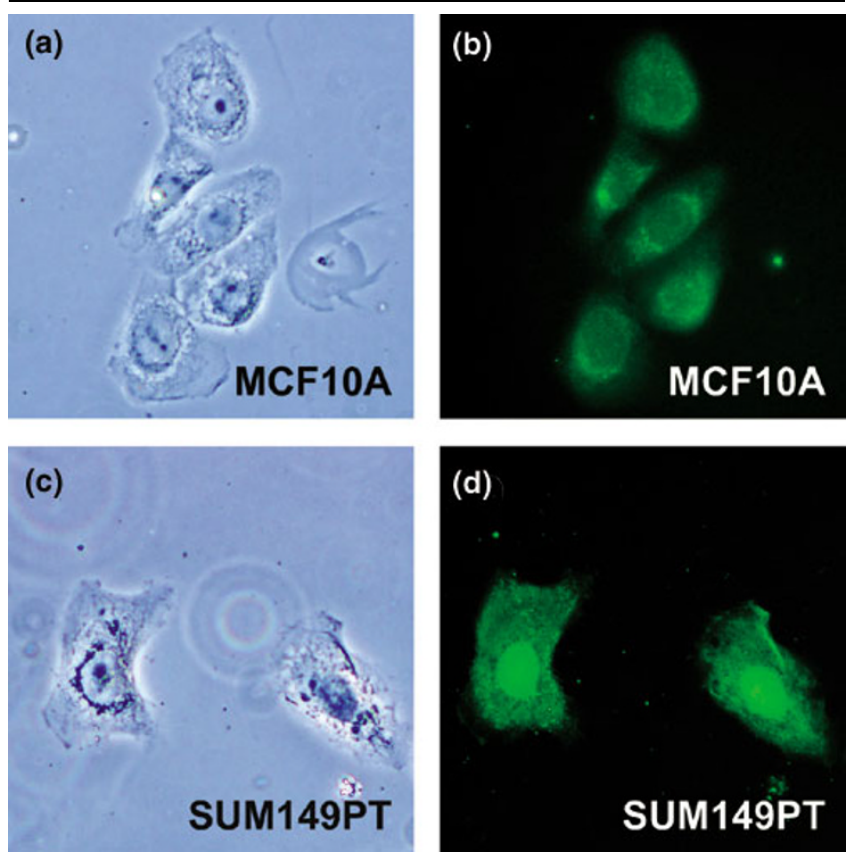

Localization of cyclin E overexpression in SUM149PT cells. (a), (c) Phase-contrast images of MCF10A cells and SUM149PT cells fixed and labeled with HE12 cyclin E primary antibody and FITC-conjugated secondary. (b), (d) Fluorescent images of the same cells visualized by fluorescence microscopy. Cyclin $\mathrm{E}$ was localized to the nucleus at low levels in the MCF10A cells and was overexpressed in the nucleus of SUM149PT cells

ined. Lung and colleagues had previously examined primary tumor tissues from 71 patients with breast cancer, and they also found no direct correlation between cyclin $E$ overexpression and chromosomal genomic instability [26].

\section{Conclusions}

We have shown that SUM149PT cells, which possess a mutation in the hCdc4 subunit of the SCF ubiquitin ligase, are unable to regulate cyclin $E$ expression. In fact, cyclin $E$ is present at elevated but stable levels on a cell per cell basis for the duration of the cell cycle in these cells. When compared with a panel of other breast cancer cell lines, cyclin E is expressed at the highest levels in SUM149PT cells. In addition, immunofluorescence showed that cyclin $E$ is being expressed in both the cytoplasm and nucleus of SUM149PT cells, in contrast to expression only in the nucleus of MCF10A cells.

Cyclin $\mathrm{E}$ overexpression has previously been implicated as a cause of genomic instability in normal HME cells [8]. The aCGH data demonstrate that SUM149PT cells have a high number of chromosomal aberrations throughout their genome. We cannot say for certain, however, that there is a cause and effect relationship between expression of cyclin E and genomic instability in the SUM149PT cells, since we observed breast cancer cell lines with many chromosomal aberrations that showed both low and high cyclin $\mathrm{E}$ levels. Cyclin $\mathrm{E}$ overexpression is thus probably only one of many factors that contribute to genomic instability in human breast cancer.

\section{Competing interests}

None declared.

\section{References}

1. D'Urso G, Marraccino RL, Marshak DR, Roberts JM: Cell cycle control of DNA replication by a homologue from human cells of the p34cdc2 protein kinase. Science 1990, 250:786-791.

2. Koff A, Giordano A, Desai D, Yamashita K, Harper JW, Elledge S, Nishimoto T, Morgan DO, Franza BR, Roberts JM: Formation and activation of a cyclin E-cdk2 complex during the G1 phase of the human cell cycle. Science 1992, 257:1689-1694.

3. Ohtsubo M, Theodoras AM, Schumacher J, Roberts JM, Pagano $\mathrm{M}$ : Human cyclin E, a nuclear protein essential for the G1-to-S phase transition. Mol Cell Biol 1995, 15:2612-2624.

4. Keyomarsi K, Conte D Jr, Toyofuku W, Fox MP: Deregulation of cyclin E in breast cancer. Oncogene 1995, 11:941-950.

5. Dou QP, Pardee AB, Keyomarsi K: Cyclin E - a better prognostic marker for breast cancer than cyclin D? [Letter]. Nat Med 1996, 2:254.

6. Buckley MF, Sweeney KJ, Hamilton JA, Sini RL, Manning DL, Nicholson RI, deFazio A, Watts CK, Musgrove EA, Sutherland RL: Expression and amplification of cyclin genes in human breast cancer. Oncogene 1993, 8:2127-2133.

7. Wimmel A, Lucibello FC, Sewing A, Adolph S, Muller R: Inducible acceleration of $\mathrm{G} 1$ progression through tetracycline-regulated expression of human cyclin E. Oncogene 1994, 9:995-997.

8. Spruck CH, Won KA, Reed SI: Deregulated cyclin E induces chromosome instability. Nature 1999, 401:297-300.

9. Keyomarsi K, Pardee AB: Redundant cyclin overexpression and gene amplification in breast cancer cells. Proc Natl Acad Sci USA 1993, 90:1112-1116.

10. Dealy MJ, Nguyen KV, Lo J, Gstaiger M, Krek W, Elson D, Arbeit J, Kipreos ET, Johnson RS: Loss of Cul1 results in early embryonic lethality and dysregulation of cyclin E. Nat Genet 1999, 23:245-248.

11. Wang Y, Penfold S, Tang X, Hattori N, Riley P, Harper JW, Cross JC, Tyers M: Deletion of the Cul1 gene in mice causes arrest in early embryogenesis and accumulation of cyclin E. Curr Biol 1999, 9:1191-1194.

12. Patton EE, Willems AR, Tyers M: Combinatorial control in ubiquitin-dependent proteolysis: don't Skp the F-box hypothesis. Trends Genet 1998, 14:236-243.

13. Strohmaier H, Spruck $\mathrm{CH}$, Kaiser $\mathrm{P}$, Won KA, Sangfelt $\mathrm{O}$, Reed SI: Human F-box protein hCdc4 targets cyclin E for proteolysis and is mutated in a breast cancer cell line. Nature 2001, 413:316-322.

14. Bai C, Sen P, Hofmann K, Ma L, Goebl M, Harper JW, Elledge SJ: SKP1 connects cell cycle regulators to the ubiquitin proteolysis machinery through a novel motif, the F-box. Cell 1996, 86:263-274.

15. Ignatoski KM, Ethier SP: Constitutive activation of pp125fak in newly isolated human breast cancer cell lines. Breast Cancer Res Treat 1999, 54:173-182.

16. Snijders AM, Nowak N, Segraves R, Blackwood S, Brown N, Conroy J, Hamilton G, Hindle AK, Huey B, Kimura K, Law S, Myambo K, Palmer J, Ylstra B, Yue JP, Gray JW, Jain AN, Pinkel D, Albertson DG: Assembly of microarrays for genome-wide measurement of DNA copy number. Nat Genet 2001, 29:263-264.

17. Snijders AM, Nowee ME, Fridlyand J, Piek JM, Dorsman JC, Jain AN, Pinkel D, van Diest PJ, Verheijen RH, Albertson DG: Genomewide-array-based comparative genomic hybridization reveals genetic homogeneity and frequent copy number increases encompassing CCNE1 in fallopian tube carcinoma. Oncogene 2003, 22:4281-4286.

18. Soule HD, Maloney TM, Wolman SR, Peterson WD Jr, Brenz R, McGrath CM, Russo J, Pauley RJ, Jones RF, Brooks SC: Isolation and characterization of a spontaneously immortalized human 
breast epithelial cell line, MCF-10. Cancer Res 1990, 50:6075-6086.

19. Harwell RM, Porter DC, Danes C, Keyomarsi K: Processing of cyclin E differs between normal and tumor breast cells. Cancer Res 2000, 60:481-489.

20. Porter DC, Keyomarsi K: Novel splice variants of cyclin E with altered substrate specificity. Nucleic Acids Res 2000, 28:E101-E108.

21. Porter DC, Zhang N, Danes C, McGahren MJ, Harwell RM, Faruki $\mathrm{S}$, Keyomarsi K: Tumor-specific proteolytic processing of cyclin E generates hyperactive lower-molecular-weight forms. Mol Cell Biol 2001, 21:6254-6269.

22. Moberg KH, Bell DW, Wahrer DC, Haber DA, Hariharan IK: Archipelago regulates Cyclin E levels in Drosophila and is mutated in human cancer cell lines. Nature 2001, 413:311-316.

23. Spruck $\mathrm{CH}$, Strohmaier $\mathrm{H}$, Sangfelt $\mathrm{O}$, Muller HM, Hubalek M, Muller-Holzner E, Marth C, Widschwendter M, Reed SI: hCDC4 gene mutations in endometrial cancer. Cancer Res 2002, 62:4535-4539.

24. Reed SE, Spruck CH, Sangfelt O, van Drogen F, Mueller-Holzner E, Widschwendter M, Zetterberg A, Reed SI: Mutation of hCDC4 leads to cell cycle deregulation of cyclin $\mathrm{E}$ in cancer. Cancer Res 2004, 64:795-800.

25. Rajagopalan $\mathrm{H}$, Jallepalli PV, Rago C, Velculescu VE, Kinzler KW, Vogelstein B, Lengauer C: Inactivation of hCDC4 can cause chromosomal instability. Nature 2004, 428:77-81.

26. Lung JC, Chu JS, Yu JC, Yue CT, Lo YL, Shen CY, Wu CW: Aberrant expression of cell-cycle regulator cyclin D1 in breast cancer is related to chromosomal genomic instability. Genes Chromosomes Cancer 2002, 34:276-284. 